\title{
Tipologi Gaya Video Instruksional di Universitas Terbuka TV
}

\author{
Isma Dwi Fiani ${ }^{1}$, Nila Kusuma Windrati ${ }^{2}$, Melisa Arisanty ${ }^{3}$, Danar Kristiana Dewi ${ }^{4}$ \\ ${ }^{1}$ Universitas Terbuka, Tangerang Selatan, Banten, Indonesia \\ e-mail: isma.fiani@ecampus.ut.ac.id
}

\begin{tabular}{|c|c|}
\hline Article Info & Abstract \\
\hline Article history: & This article explains the typology of instructional video styles in Universitas Terbuka \\
\hline Received & TV (UT TV) as a learning medium in open and distance higher education. Instruc- \\
\hline Apr $12^{\text {th }}, 2021$ & tional video styles are an essential aspect of learning media because they relate to \\
\hline Revised & student involvement in the learning process. This research used a descriptive content \\
\hline May $26^{\text {th }}, 2021$ & analysis method to obtain and determine the style of communication in each video \\
\hline Accepted & studied. The result indicates that the instructional video style on UT TV tends to be \\
\hline May $26^{\text {th }}, 2021$ & consistent across subjects and disciplines. The style used by most instructional videos \\
\hline Published & on UT TV is slide style, both as the main style and as a secondary style. The slide \\
\hline July $30^{\text {th }}, 2021$ & $\begin{array}{l}\text { style is identical to the presentation format in conventional lectures, where slides are } \\
\text { positioned as teaching aids so learning material can easily be understood. }\end{array}$ \\
\hline
\end{tabular}

Keywords: instructional video; distance education; communication style; content analysis

\begin{abstract}
Abstrak
Artikel ini berusaha memaparkan tipologi gaya video instruksional di Universitas Terbuka TV (UT TV) sebagai media pembelajaran di Pendidikan Tinggi Terbuka dan Jarak Jauh (PTTJJ). Gaya video instruksional merupakan aspek penting dalam media pembelajaran sebab berkaitan dengan tingkat keterlibatan mahasiswa dalam proses pembelajaran. Penelitian ini menggunakan metode analisis isi deskriptif untuk mengidentifikasi gaya komunikasi pada setiap video yang diteliti. Hasil penelitian ini menunjukkan bahwa video instruksional di UT TV memiliki gaya komunikasi yang cenderung seragam di seluruh mata pelajaran dan disiplin ilmu. Gaya yang digunakan di sebagian besar video instruksional di UT TV adalah gaya slide, baik sebagai gaya utama maupun gaya pendukung. Gaya slide sangat identik dengan format presentasi pada perkuliahan konvensional, di mana slide diposisikan sebagai alat bantu pengajar saat menyampaikan materi agar mudah dipahami oleh mahasiswa.
\end{abstract}

Kata Kunci: video instruksional; pendidikan jarak jauh; gaya komunikasi; analisis isi 


\section{PENDAHULUAN}

Perkembangan teknologi dewasa ini semakin menitikberatkan pada inovasi di bidang-bidang strategis, salah satunya adalah bidang pendidikan. Sejak teknologi informasi dan komunikasi semakin berkembang, terutama sejak lahirnya Web 2.0, muncul suatu kondisi di mana teknologi terintegrasi ke dalam proses belajar-mengajar. Salah satu bentuk pendidikan yang sangat didukung oleh perkembangan ini adalah pendidikan jarak jauh (PJJ).

PJJ memiliki beberapa karakteristik, salah satunya menggunakan media komunikasi yang berbasis teknologi. Hal ini disebabkan karena media dapat menjadi penghubung keterpisahan antara pendidik dan siswa (Padmo \& Pribadi, 2002). Media yang digunakan dalam PJJ sangat beragam, salah satunya berbentuk video, atau yang sering disebut sebagai video instruksional. Berdasarkan beberapa penelitian, video dapat mendukung efektifitas pengajaran dan pembelajaran yang sama tingginya dengan cara tatap muka (Zhang, 2006). Selain itu, video instruksional lazim digunakan dalam pendidikan jarak jauh (PJJ) karena dapat digunakan sebagai media belajar mandiri.

Menurut Klass (Hartsell \& Yuen, 2006), video instruksional berperan dalam menghantarkan materi pembelajaran dan memungkinkan mahasiswa menggunakan indera visual dan auditori dalam memahami konsep dan prosedur yang kompleks melalui pesan teks dan grafik yang sederhana. Zhang (2006) mengatakan bahwa media pembelajaran berbentuk video memungkinkan mahasiswa untuk melihat objek secara aktual dan realistis, melihat urutan dalam gerakan, sekaligus mendengarkan narasi. Menurut Michelich (Hartsell \& Yuen, 2006) dalam penyampaian instruksi, materi berbasis multimedia juga dapat menambah interaktivitas pada materi berbasis teks yang stagnan (Michelich, 2002).

Universitas Terbuka (UT), sebagai perguruan tinggi pertama yang menerapkan Sistem Belajar Jarak Jauh (SBJJ) di Indonesia, telah mengembangkan bahan ajar yang memungkinkan mahasiswa belajar secara mandiri. Bermula dari bahan ajar cetak, atau yang biasa disebut modul, UT saat ini terus mengembangkan materi pembelajaran mahasiswa dalam berbagai bentuk, salah satunya video.

Materi pembelajaran UT dalam bentuk video dapat diakses dalam berbagai cara, salah satunya adalah UT TV melalui online streaming di YouTube. UT TV merupakan salah satu dari layanan SUAKA, atau sumber pembelajaran terbuka. Di dunia pendidikan, SUAKA dikenal sebagai Open Educational
Resources (OER). Downes (Grosseck \& Malita, 2017), mengatakan bahwa OER adalah materi yang digunakan untuk mendukung aktivitas pendidikan, biasanya dapat diakses, digunakan, dimodifikasi dan dibagikan secara bebas. Oleh karena itu, UT TV sebagai OER menyediakan video instruksional yang dapat diakses secara gratis, baik oleh mahasiswa maupun masyarakat luas.

Kemajuan teknologi memungkinkan institusi pendidikan untuk membuat dan menyalurkan materi pembelajaran dalam berbagai format. Namun, tantangannya adalah bagaimana cara mengembangkan bahan ajar yang sesuai dengan preferensi mahasiswa. Kizilcec, Bailenson dan Gomez (2015) misalnya, melakukan penelitian untuk mengukur efektivitas desain instruksional audiovisual dengan mengidentifikasi apakah siswa lebih suka menerima informasi secara visual (misal dalam bentuk grafik) atau secara verbal (misal dalam teks tertulis atau lisan).

Peran penting video instruksional dalam pembelajaran jarak jauh telah mendorong beberapa peneliti untuk mengembangkan penelitian yang berpusat pada efektivitas video instruksional. Beberapa penelitian tersebut menunjukkan bahwa gaya komunikasi pada video instruksional berperan penting pada tingkat keterlibatan siswa dalam proses belajar secara online. Penelitian Guo, Kim dan Rubin (2014) menunjukkan bahwa video yang menampilkan slide yang disertai video instruktur dianggap lebih menarik daripada yang menampilkan slide saja. Namun, dibandingkan slide PowerPoint, gaya komunikasi 'khan-style tablet drawing' dianggap lebih menarik. Hal ini menunjukkan pentingnya gaya komunikasi di video instruksional bagi audiensnya.

Berdasarkan latar belakang tersebut, penelitian ini dilakukan untuk mengetahui tipologi gaya komunikasi pada video instruksional UT TV. Menurut Kamus Merriam-Webster, tipologi merupakan studi tentang tipe untuk membuat klasifikasi berdasarkan tipe atau kategori. Peneliti mengidentifikasi gaya komunikasi pada video instruksional di Universtas Terbuka berdasarkan konsep yang dikembangkan oleh Espino dan Artal (2016) serta konsep atribut utama video instruksional yang dikembangkan oleh Guo P.J (2014).

Atribut tersebut diharapkan dapat menjadi dasar tipologi video instruksional UT, sehingga dapat menjadi data awal di penelitian selanjutnya tentang efektivitas video instruksional di Universitas Terbuka berdasarkan karakteristik gaya komunikasi tersebut. Peneliti memilih video instruksional di UT TV sebab 
medium ini berbasis online dan berada pada platform yang sangat populer, yaitu YouTube. Sehingga hasil penelitian ini diharapkan dapat sejalan dengan posisi UT sebagai sebagai cyber university.

\section{METOD}

Penelitian ini dilaksanakan dalam dua langkah. Pertama, menggunakan metode analisis isi deskriptif untuk mengidentifikasi gaya komunikasi pada video instruksional di UT TV. Kemudian, sebagai data pendukung, peneliti menggunakan metode kualitatif untuk menggali apa saja yang dilakukan pada tahap pra-produksi video instruksional di UT TV, terutama kaitannya dengan pemilihan gaya komunikasi.

Analisis isi merupakan sebuah metode penelitian yang menggunakan simbol atau teks di media sebagai objeknya. Krippendorff (2004) menjelaskan bahwa analisis isi merupakan teknik penelitian dengan deskripsi obyektif, sistematis dan kuantitatif tentang konten media. Analisis isi menggunakan prosedur yang sistematis dalam mengkoding suatu pesan simbolik (berupa teks, gambar, dll). Bauer (Herring , 2009) mengatakan bahwa dalam penelitian ilmu komunikasi, analisis isi mengidentifikasi struktur pesan, misalnya panjang pesan, distribusi teks, atau komponen gambar tertentu, dan tema semantik. Tujuan analisis isi adalah untuk mengidentifikasi dan menggambarkan pola dalam konten, dengan mempertimbangkan apa yang dirasakan audiens melalui indra, alih-alih apa yang dirasakan atau dipercayai sebagai hasil dari konten itu, atau apa yang diinginkan oleh pembuat konten (Herring, 2009).

Metode analisis isi dalam penelitian ini digunakan dalam mengidentifikasi gaya komunikasi dan atribut utama dalam video instruksional di UT TV. Dalam penerapannya, setiap yang tampak dimasukkan ke dalam kategori yang telah ditetapkan ke dalam lembar kerja koding. Data tersebut kemudian dianalisis menggunakan metode analisis isi untuk mendapatkan dan menentukan gaya komunikasi pada setiap video yang diteliti. Karena menggunakan analisis isi deskriptif, maka penelitian ini tidak bermaksud untuk menguji hipotesis atau hubungan di antara variabel.

Analisis isi memerlukan unit analisis, yaitu bagian dari isi yang akan diamati, misalnya berupa kata-kata, gambar, potongan adegan dan sebagainya. Tak sampai di situ, pada unit analisis tersebut juga harus ditentukan unit sampel dan unit pencatatannya. Unit sampel merupakan isi apa yang akan dianalisis, sedangkan unit pencatatan mengacu pada bagian mana dari unit sampel yang akan dilakukan coding dan penghitungan (Eriyanto, 2011). Unit analisis pada penelitian ini adalah sebagai berikut:

Tabel 1. Unit Analisis

\begin{tabular}{ll}
\hline \multicolumn{1}{c}{ Unit Analisis } & \multicolumn{1}{c}{ Kategori } \\
\hline & Talking head \\
& Live lecure \\
& Wawancara \\
& Slides \\
Gaya produksi & Screencast \\
& Virtual whiteboard \\
& Dokumenter \\
& Animasi \\
& Demonstrasi \\
\hline & $48-130$ kata/menit \\
& $130-145 \mathrm{kata} /$ menit \\
& $145-165 \mathrm{kata} /$ menit \\
Kecepatan berbicara & $165-185 \mathrm{kata} /$ menit \\
& $185-254 \mathrm{kata} /$ menit \\
\hline Tipe video & Perkuliahan \\
& Tutorial \\
\hline \multirow{2}{*}{ Peran pelajar/pemirsa } & Orang kedua \\
& Orang ketiga \\
\hline \multirow{2}{*}{ Seting latar } & Natural (kelas, ruangan \\
& kantor, \\
& Artifisial (chroma display, \\
& computer screenshot) \\
\hline &
\end{tabular}

Unit sampel pada penelitian analisis isi memberikan batasan secara tegas antara isi mana yang akan diteliti dan tidak akan diteliti sesuai dengan tujuan penelitian (Eriyanto, 2011). Penarikan sampel tayangan akan dilakukan secara acak menggunakan prosedur stratified random sampling agar sampel dapat mewakili masing-masing program studi.

Penelitian ini menggunakan data primer berupa video instruksional di YouTube UT TV. Sedangkan data sekunder pada penelitian ini adalah pustaka yang relevan dengan topik penelitian dan wawancara dengan tim produksi video instruksional di UT TV, dalam hal ini adalah Pusat Pengembangan Multi Media (P2M2) Universitas Terbuka.

\section{HASIL DAN PEMBAHASAN}

Penelitian ini menganalisis bagaimana gaya video instruksional di UT TV. Secara keseluruhan, terdapat 365 video instruksional yang diunggah di UT TV sejak 2017. Secara keseluruhan, ada 32 program studi dan bidang ilmu yang memiliki video instruksional di UT TV. Program studi dengan video 
Tabel 2. Jumlah Video Instruksional di UT TV Berdasarkan Program Studi

\begin{tabular}{|c|c|c|}
\hline No & Program Studi & $\begin{array}{c}\text { Jumlah } \\
\text { Video }\end{array}$ \\
\hline 1 & Manajemen & 94 \\
\hline 2 & Ekonomi Pembangunan & 42 \\
\hline 3 & Pendidikan Bahasa Inggris & 27 \\
\hline 4 & Kearsipan & 24 \\
\hline 5 & Magister Ilmu Kelautan & 23 \\
\hline 6 & Ilmu Administrasi Negara & 16 \\
\hline 7 & $\begin{array}{l}\text { Pendidikan Pancasila dan } \\
\text { Kewarganegaraan }\end{array}$ & 13 \\
\hline 8 & Agribisnis & 11 \\
\hline 9 & Akuntansi & 10 \\
\hline 10 & Pengantar Ilmu Sosial & 10 \\
\hline 11 & PGSD & 10 \\
\hline 12 & Magister Ilmu Administrasi & 9 \\
\hline 13 & PGPAUD & 9 \\
\hline 14 & Pendidikan Ekonomi & 9 \\
\hline 15 & Biologi & 8 \\
\hline 16 & Magister Pendidikan Matematika & 8 \\
\hline 17 & $\begin{array}{l}\text { Pendidikan Bahasa dan Sastra } \\
\text { Indonesia }\end{array}$ & 8 \\
\hline 18 & Pendidikan Fisika & 8 \\
\hline 19 & Sosiologi & 7 \\
\hline 20 & Ilmu Administrasi Bisnis & 6 \\
\hline 21 & Ilmu Hukum & 6 \\
\hline 22 & Perpajakan & 6 \\
\hline 23 & Pendidikan Kimia & 6 \\
\hline 24 & Pendidikan Biologi & 5 \\
\hline 25 & Pendidikan Matematika & 4 \\
\hline 26 & Ilmu Pemerintahan & 3 \\
\hline 27 & Kimia Dasar & 3 \\
\hline 28 & Ilmu Komunikasi & 3 \\
\hline 29 & Pendidikan Bahasa Inggris & 2 \\
\hline 30 & Magister Pendidikan Dasar & 2 \\
\hline 31 & Teknologi Pangan & 2 \\
\hline 32 & Matematika & 1 \\
\hline
\end{tabular}

instruksional terbanyak adalah Manajemen, yaitu sebanyak 94 video, kemudian diikuti oleh Program Studi Ekonomi Pembangunan sebanyak 42 video.

Seperti yang telah dijelaskan sebelumnya bahwa penelitian ini tidak melibatkan seluruh video yang ada di UT TV, melainkan hanya 55 video instruksional yang dipilih melalui prosedur random sampling yang mewakili masing-masing program studi. Hasil analisis isi terhadap 55 video instruksional tersebut menunjukkan bahwa terdapat 5 gaya video instruksional di UT TV yaitu Slides, Dokumenter, Wawancara, Talking Head dan Mix. Setiap gaya tersebut memiliki frekuensi penggunaan yang berbeda. Namun secara umum, gaya yang paling banyak digunakan dalam video instruksional di UT TV adalah slides.

Apabila dikategorikan berdasarkan bidang ilmu, terdapat perbedaan penggunaan gaya komunikasi pada video instruksional. Kategori bidang ilmu yang ada di UT antara lain Ilmu Sosial, Ilmu Alam dan Matematika, Ekonomi dan Manajemen, Teknik dan Teknologi, dan Keguruan dan Ilmu Pendidikan. Tabel 3 menunjukkan data mengenai penggunaan gaya komunikasi video instruksional di masing-masing bidang ilmu tersebut. Tabel tersebut menunjukkan bahwa gaya Slides paling banyak digunakan pada video instruksional berdasarkan bidang ilmu. Gaya lain, sebut saja Talking Head, hanya digunakan oleh ilmu sosial dan bidang keguruan/ilmu pendidikan dengan jumlah tidak lebih dari 2 video.

\section{Gaya Slide dan Presenter pada Video Instruksional}

Slide dan presenter merupakan gaya video instruksional yang memadukan slide dengan video instruktur/pembicara yang menjelaskan materi yang mengacu pada slide. Sehingga, apa yang disampaikan oleh instruktur dengan materi yang tertulis pada slide sifatnya saling mendukung. Sehingga, gaya video ini pada dasarnya mengemas materi ke dalam pesan verbal tulisan, verbal lisan, dan komunikasi nonverbal pada mimik dan bahasa tubuh instruktur.

Tabel 3. Penggunaan Gaya Komunikasi Video Instruksional berdasarkan Bidang Ilmu

\begin{tabular}{ccccccccccc}
\hline \multirow{2}{*}{ Gaya Video } & \multicolumn{2}{c}{ Ilmu Sosial } & \multicolumn{2}{c}{$\begin{array}{c}\text { Ilmu Alam dan } \\
\text { Matematika }\end{array}$} & \multicolumn{2}{c}{$\begin{array}{c}\text { Ekonomi dan } \\
\text { Manajemen }\end{array}$} & $\begin{array}{c}\text { Teknik dan } \\
\text { Teknologi }\end{array}$ & \multicolumn{2}{c}{$\begin{array}{c}\text { Keguruan dan } \\
\text { Ilmu Pendidikan }\end{array}$} \\
\cline { 2 - 12 } & $\mathrm{N}$ & $\%$ & $\mathrm{~N}$ & $\%$ & $\mathrm{~N}$ & $\%$ & $\mathrm{~N}$ & $\%$ & $\mathrm{~N}$ & $\%$ \\
\hline Slide dan Presenter & 14 & $25 \%$ & 8 & $15 \%$ & 5 & $9 \%$ & 2 & $4 \%$ & 15 & $27 \%$ \\
Dokumenter & 2 & $4 \%$ & 2 & $4 \%$ & 0 & $0 \%$ & 0 & $0 \%$ & 0 & $0 \%$ \\
Wawancara & 1 & $2 \%$ & 0 & $0 \%$ & 0 & $0 \%$ & 0 & $0 \%$ & 0 & $0 \%$ \\
Talking Head & 1 & $2 \%$ & 0 & $0 \%$ & 0 & $0 \%$ & 0 & $0 \%$ & 2 & $4 \%$ \\
Mix & 0 & $0 \%$ & 0 & $0 \%$ & 0 & $0 \%$ & 0 & $0 \%$ & 2 & $4 \%$ \\
\hline
\end{tabular}


IKOMIK: Jurnal Ilmu Komunikasi dan Informasi 1(1) 2021 40-47

Tabel 4. Penggunaan Gaya Slide dan Presenter berdasarkan Bidang Ilmu

\begin{tabular}{|c|c|c|c|c|c|c|c|c|c|}
\hline \multicolumn{2}{|c|}{ Ilmu Sosial } & \multicolumn{2}{|c|}{$\begin{array}{l}\text { Ilmu Alam dan } \\
\text { Matematika }\end{array}$} & \multicolumn{2}{|c|}{$\begin{array}{c}\text { Ekonomi dan } \\
\text { Manajemen }\end{array}$} & \multicolumn{2}{|c|}{$\begin{array}{l}\text { Teknik dan } \\
\text { Teknologi }\end{array}$} & \multicolumn{2}{|c|}{$\begin{array}{l}\text { Keguruan dan } \\
\text { Ilmu Pendidikan }\end{array}$} \\
\hline $\mathrm{N}$ & $\%$ & $\mathrm{~N}$ & $\%$ & $\mathrm{~N}$ & $\%$ & $\mathrm{~N}$ & $\%$ & $\mathrm{~N}$ & $\%$ \\
\hline 14 & $25 \%$ & 8 & $15 \%$ & 5 & $9 \%$ & 2 & $4 \%$ & 15 & $27 \%$ \\
\hline
\end{tabular}

Gaya video slide dan presenter biasanya menampilkan instruktur dengan medium shoot, sehingga visualnya berfokus pada gestur wajah dan setengah badan. Gaya ini mengingatkan pada pembaca berita di televisi, karena memang sifatnya penyampaian materi pembelajaran secara informatif, tanpa memperagakan/ mendemonstrasikan apa yang sedang dijelaskan. Sebagian besar video instruksional menampilkan pembicara secara bergantian dengan slide. Sedangkan lainnya hanya menampilkan pembicara pada awal dan akhir video.

Karakteristik slide itu sendiri adalah untuk menampilkan materi pembelajaran berupa halaman teks dan grafik. Istilah slide memiliki makna yang serupa dengan slide PowerPoint atau proyektor, yaitu merupakan media presentasi/penyampaian materi yang ditampilkan dalam layar, dan dalam penyajiannya dinavigasikan oleh presenter. Bentuk pesan yang disampaikan dalam slide dapat berupa teks dan grafik, karena slide merupakan alat bantu presenter saat menyampaikan materi. Sehingga, slide berperan untuk "memberdayakan" presenter.

Dalam konteks video instruksional di UT $\mathrm{TV}$, slide dan presenter digunakan secara dominan sebagai gaya komunikasi utama. Hal ini terlihat pada Tabel 4.1 yang menggambarkan bagaimana 44 video, atau $80 \%$ dari seluruh sampel video di penelitian ini menggunakan gaya komunikasi ini. Berdasarkan Tabel 4.3, bidang keilmuan yang paling banyak menggunakan gaya komunikasi slide berdasarkan sampel penelitian adalah Keguruan dan Ilmu Pendidikan sebanyak 27\%, kemudian diikuti dengan Ilmu Sosial sebanyak 25\%.

Selain frekuensi penggunaannya, penelitian ini juga mengidentifikasi bagaimana gaya komunikasi ini dipresentasikan dalam video instruksional, serta bagaimana ciri utama gaya video ini. Hal ini sangat berkaitan dengan gaya pendukung yang berhasil diidentifikasi.

Gaya pemaparan presenter memainkan posisi penting pada video slide dan presenter. Salah satu aspek gaya pemaparan instruktur adalah kecepatan berbicara, serta gaya berbicaranya, apakah menggunakan script atau non-scripted/spontan. Gambar 4.3 menggambarkan gaya berbicara instruktur berdasarkan kecepatan berbicara dan tingkat spontanitasnya. Grafik tersebut memperlihatkan bahwa sebagaian besar presenter/pemateri pada video ini berbicara dengan kecepatan yang lambat (48-80 $\mathrm{kata} /$ menit).

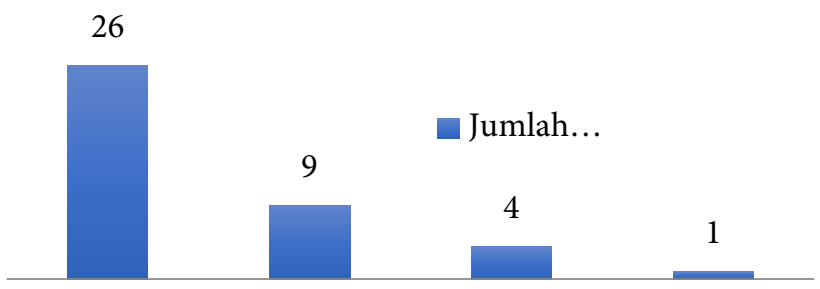

Lambat (48- Sedang (80 - Cepat (110 - Sangat Cepat $80 \quad 110 \quad 140 \quad(140-170$ kata/menit) kata/menit) kata/menit) kata/menit)

Gambar 1. Kecepatan Berbicara pada Video Slide dan Presenter

Penelitian ini juga mengeksplorasi penggunaan seting latar pada video instruksional yang menampilkan sosok presenter atau pemateri. Dari hasil identifikasi, terdapat dua seting latar yang digunakan dalam gaya slide dan presenter, yaitu seting latar artifisial dan seting latar studio. Sebanyak 63\%, atau dengan kata lain mayoritas video dengan gaya slide dan presenter menggunakan seting latar studio. Sedangkan seting latar artifisial digunakan sebanyak 37\% video dengan gaya ini.

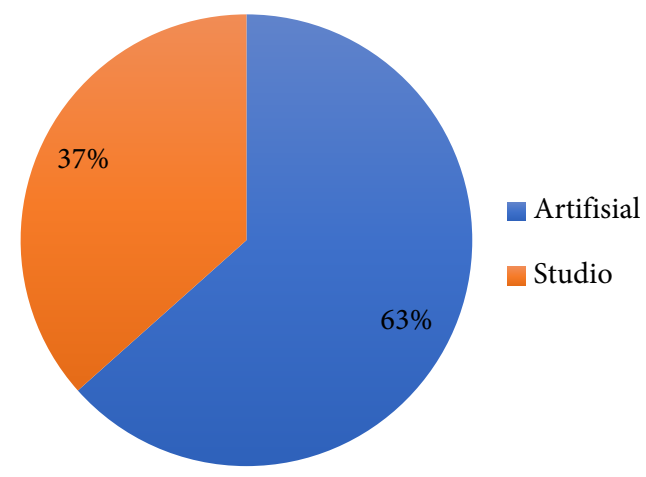

Gambar 2. Seting Latar pada Video dengan Gaya Slide dan Presenter 


\section{Wawancara dan Slide pada Video Instruksional}

Video dengan bentuk wawancara menampilkan atau atau lebih orang menjawab pertanyaan tentang atau mendiskusikan suatu topik. Pendekatan utama dalam video instruksional dengan gaya wawancara yaitu bersifat dialogis, yaitu beberapa orang terlibat dalam percakapan tentang suatu topik. Pendekatan ini serupa dengan format gelar wicara (talkshow) di televisi yang menampilkan perbincangan atau diskusi pembawa acara dengan sekelompok atau seorang «tamu» mengenai topik tertentu dan dipandu oleh pembawa acara. Seseorang yang ditampilkan sebagai "tamu" merupakan seorang ahli atau seseorang yang memiliki pengalaman luas mengenai topik yang diangkat.

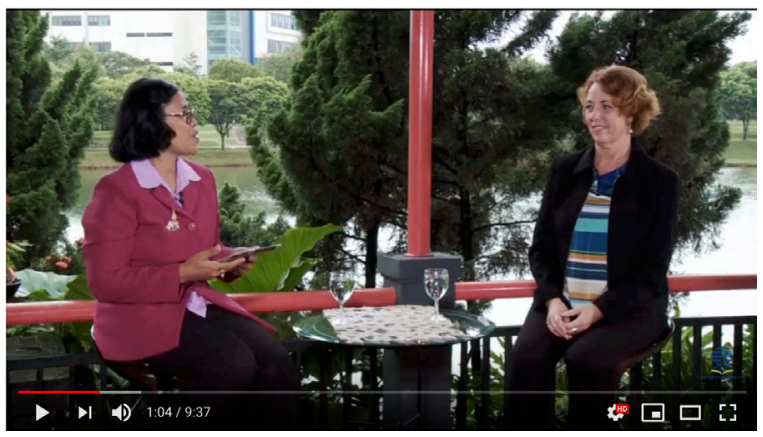

Gambar 3. Gaya Wawancara pada Video Instruksional

Contoh dari video instruksional dengan gaya wawancara adalah mata kuliah PBIS4208 (READING II - Main Idea). Video tersebut menampilkan dialog antara pewawancara dan seseorang yang diwawancara mengenai suatu topik atau materi. Seperti format wawancara pada video instruksional pada umumnya, video di UT TV dengan gaya ini memiliki pendekatan yang sama seperti membawa dosen tamu atau ahli ke dalam kelas untuk memaparkan materi yang mereka kuasai.

Gaya video wawancara di UT TV memiliki karakteristik penting lainnya, yaitu saat pembicara menjelaskan materi, ia tidak mengarahkan pembicaraannya secara langsung kepada audiens. Karakteristik ini ditandai dengan kontak mata yang tidak menatap audiens. Karakteristik ini juga memosisikan pelajar/audiens sebagai orang ketiga. Meskipun demikian, terdapat sapaan secara langsung dari pembawa acara dan pembicara kepada audiens di bagian pembukaan.

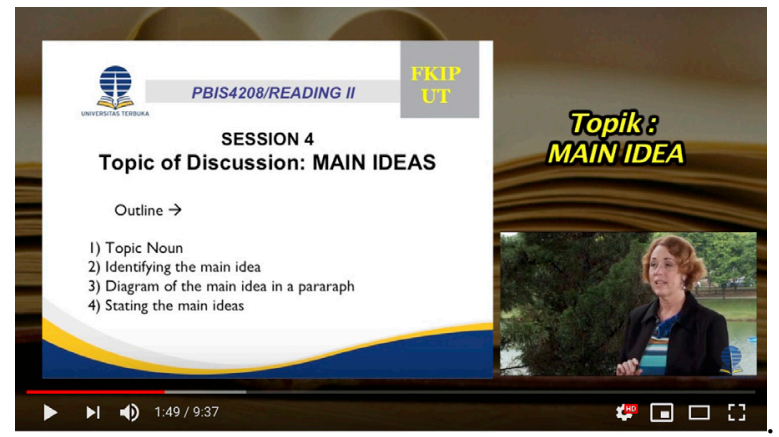

Gambar 4. Gaya Slide dan Wawancara pada Video Instruksional

\section{Gaya Talking-Heads pada Video Instruksional}

Talking head merupakan salah satu gaya produksi yang digunakan oleh Universitas Terbuka pada video instruksionalnya. Karakteristik gaya video ini adalah berfokus pada pengajar yang menatap kamera seperti sedang berbicara secara langsung kepada audiens, sehingga audiens/mahasiswa diperlakukan sebagai orang kedua. Selain itu, pengajar biasanya ditampilkan secara dominan dalam frame, namun ada beberapa teks yang diperlihatkan untuk untuk menegakkan ide-ide kunci dari narasi atau adegan beralih untuk menunjukkan jenis materi lain (gambar foto, klip video pendek, dll.). Berdasarkan Tabel 5, bidang ilmu keguruan dan ilmu pendidikan paling banyak menggunakan gaya video instruksional ini.

Contoh dari video instruksional dengan gaya talking head adalah mata kuliah Ekonomi Pembangunan Perikanan (MMPI5204) yang cuplikannya dapat dilihat pada Gambar 5. Video tersebut secara dominan menampilkan seorang pengajar yang menatap kamera seperti sedang berbicara secara langsung kepada audiens tanpa bantuan slide atau alat peraga lainnya.

Tabel 5. Penggunaan Gaya Talkin-Heads berdasarkan Bidang Ilmu

\begin{tabular}{|c|c|c|c|c|c|c|c|c|c|}
\hline \multicolumn{10}{|c|}{ Bidang Ilmu } \\
\hline \multicolumn{2}{|c|}{ Ilmu Sosial } & \multicolumn{2}{|c|}{$\begin{array}{c}\text { Ilmu Alam dan } \\
\text { Matematika }\end{array}$} & \multicolumn{2}{|c|}{$\begin{array}{l}\text { Ekonomi dan } \\
\text { Manajemen }\end{array}$} & \multicolumn{2}{|c|}{$\begin{array}{c}\text { Teknik dan } \\
\text { Teknologi }\end{array}$} & \multicolumn{2}{|c|}{$\begin{array}{c}\text { Keguruan } \\
\text { dan Ilmu } \\
\text { Pendidikan }\end{array}$} \\
\hline $\mathrm{N}$ & $\%$ & $\mathrm{~N}$ & $\%$ & $\mathrm{~N}$ & $\%$ & $\mathrm{~N}$ & $\%$ & $\mathrm{~N}$ & $\%$ \\
\hline 1 & $2 \%$ & 0 & $0 \%$ & 0 & $0 \%$ & 0 & $0 \%$ & 2 & $4 \%$ \\
\hline
\end{tabular}




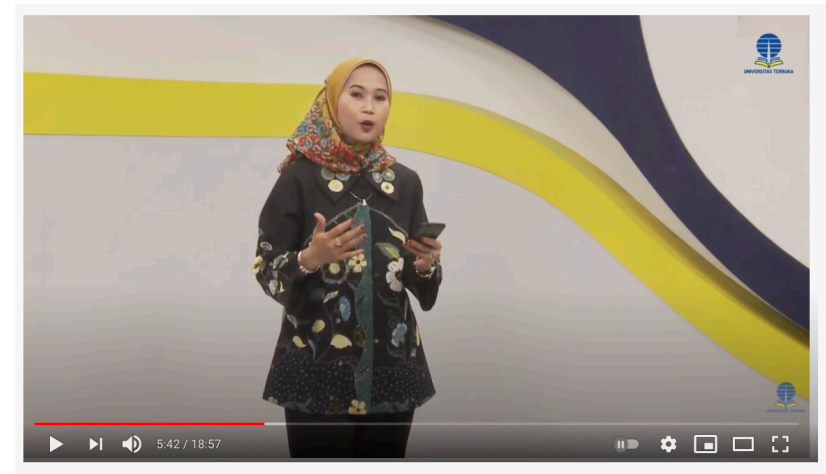

Industri 4.0 Dalam Konteks Pembangunan Perikanan - MMPI5204 Ekonomi Pembangunan Perikanan 549 views $\cdot 24$ Feb 2020 90 9I0 $\rightarrow$ SHARE $\equiv+$ SAVE

Gambar 5. Gaya Talking Head pada Video Instruksional

Dalam konteks kecepatan berbicara, hasil penelitian ini memperlihatkan bahwa sebagaian besar presenter/pemateri pada video ini berbicara dengan kecepatan yang lambat (80-110 kata/menit). Hal tersebut tersaji dalam grafik di Gambar 6.

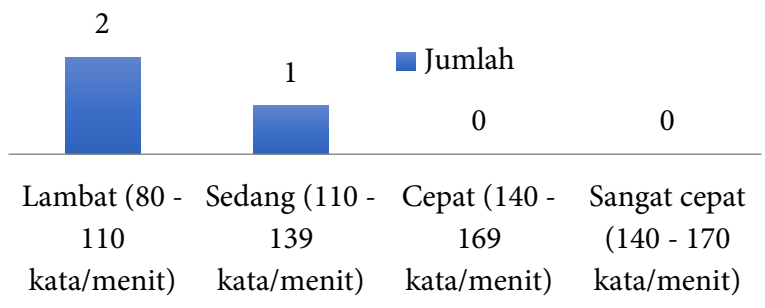

Gambar 6. Kecepatan Berbicara pada Gaya Talking Head
Terdapat dua jenis setting latar yang digunakan dalam gaya talking head, yaitu setting latar artifisial dan seting latar studio. Sebagian besar dari gaya video ini menggunakan setting latar artifisial, yaitu sebanyak 2 dari 3 sampel video, sedangkan sebagian kecil lainnya menggunakan setting latar classroom.

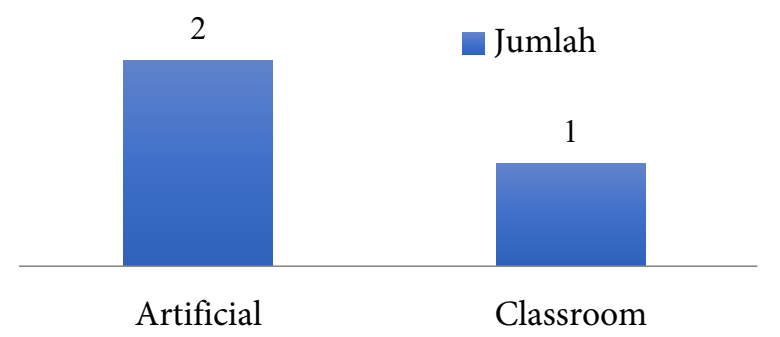

Gambar 7. Kecepatan Berbicara pada Gaya Talking Head

\section{Gaya Dokumenter pada Video Instruksional}

Dokumenter merupakan gaya video instruksional yang menggunakan segmen film bernarasi hampir di sepanjang video. Gaya dokumenter lazim digunakan dalam video instruksional dengan menekankan pada sinematografi yang strukturnya terdiri dari narasi dan segmen film tentang suatu topik. Dalam konteks UT TV, bidang ilmu sosial dan ilmu alam/matematika paling banyak menggunakan gaya video instruksional ini. Hal tersebut dapat dilihat pada Tabel 6.

Tabel 6. Penggunaan Gaya Dokumenter berdasarkan Bidang Ilmu

\begin{tabular}{|c|c|c|c|c|c|c|c|c|c|}
\hline \multicolumn{10}{|c|}{ Bidang Ilmu } \\
\hline \multicolumn{2}{|c|}{ Ilmu Sosial } & \multicolumn{2}{|c|}{$\begin{array}{c}\text { Ilmu Alam dan } \\
\text { Matematika }\end{array}$} & \multicolumn{2}{|c|}{$\begin{array}{l}\text { Ekonomi dan } \\
\text { Manajemen }\end{array}$} & \multicolumn{2}{|c|}{$\begin{array}{l}\text { Teknik dan } \\
\text { Teknologi }\end{array}$} & \multicolumn{2}{|c|}{$\begin{array}{l}\text { Keguruan dan } \\
\text { Ilmu Pendidikan }\end{array}$} \\
\hline $\mathrm{N}$ & $\%$ & $\mathrm{~N}$ & $\%$ & $\mathrm{~N}$ & $\%$ & $\mathrm{~N}$ & $\%$ & $\mathrm{~N}$ & $\%$ \\
\hline 2 & $4 \%$ & 2 & $4 \%$ & 0 & $0 \%$ & 0 & $0 \%$ & 0 & $0 \%$ \\
\hline
\end{tabular}

Gaya dokumenter di video instruksional UT TV memiliki struktur yang serupa dengan video dokumenter pada umumnya, yaitu terdiri dari narasi audio dan segmen film. Namun, materi yang diangkat cenderung dijelaskan secara komperhensif pada narasi audio. Sebaliknya, visualisasi berupa film (gambar bergerak) cenderung berperan sebagai pendukung narasi yang disampaikan oleh narator di video tersebut. Sehingga, film yang diangkat di dalam video dokumenter di UT TV tidak memiliki alur cerita yang lengkap, lebih seperti potongan-potongan video yang mendukung materi yang disampaikan oleh narrator. Sehingga dapat disimpulkan bahwa gaya ini lebih menekankan pada narasi audio dibandingkan visual. Contoh dari video instruksional dengan gaya dokumenter adalah mata kuliah Pendidikan Kewirausahaan (PKOP4206) yang cuplikannya dapat dilihat pada Gambar 8.

Narator sebagai elemen yang berperan penting di dalam gaya ini ditampilkan hanya pada pembukaan dan penutup saja. Selebihnya, fisik narator tidak ditonjolkan, melainkan hanya suaranya saja. Dalam konteks kecepatan berbicara, hasil penelitian ini memperlihatkan bahwa sebagaian besar presenter/ pemateri pada video ini berbicara dengan kecepatan yang lambat (80-110 kata/menit). Hal tersebut tersaji dalam grafik di Gambar 9. 


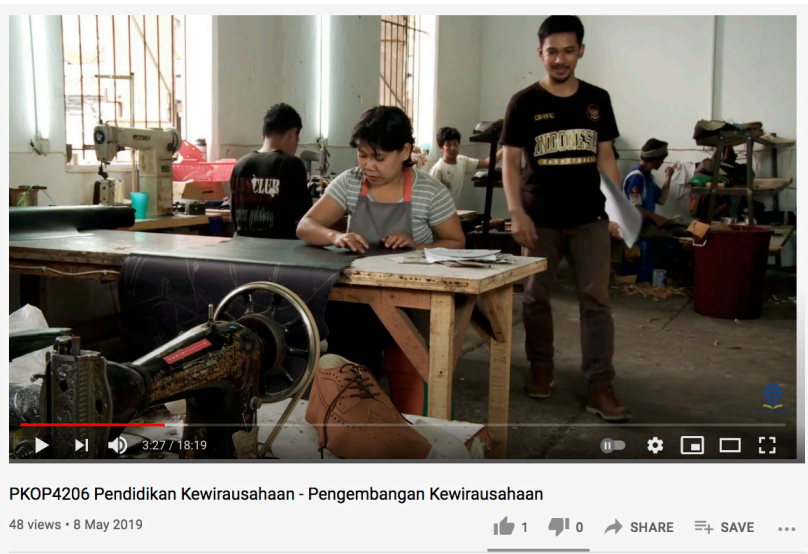

Gambar 8. Gaya Dokumenter pada Video Instruksional

3

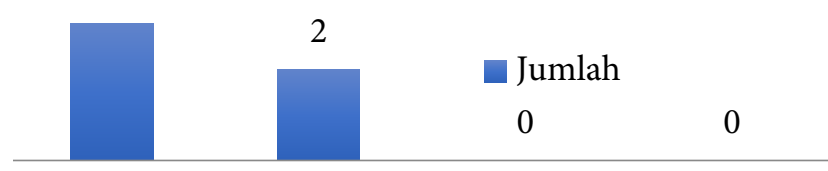

Lambat (80 - Sedang (110 - Cepat (140 - Sangat cepat $\begin{array}{llll}110 & 139 & 169 & (140-170\end{array}$ kata/menit) kata/menit) kata/menit) kata/menit)

Gambar 9. Kecepatan Berbicara pada Gaya Dokumenter

\section{Pembahasan}

Hasil penelitian ini menunjukkan bahwa gaya video yang digunakan di setiap video tidaklah tunggal. Setiap video memiliki lebih dari satu gaya produksi dan memadukannya dengan gaya produksi lain. Meskipun demikian, ada satu gaya yang paling menonjol di masing-masing video instruksional. Peneliti menyebutnya sebagai "Gaya Produksi Utama". Sedangkan gaya produksi yang muncul namun tidak dominan disebut sebagai "Gaya Produksi Pendukung". Berdasarkan hal ini, penelitian selanjutnya dapat menggali pengaruh dari setiap gaya yang digunakan dalam video instruksional, baik sebagai yang utama maupun sebagai pendukung, terhadap student engagement dalam pendidikan jarak jauh.

\section{SIMPULAN}

Berdasarkan hasil penelitian ini, dapat disimpulkan bahwa video instruksional di UT TV menunjukkan gaya komunikasi yang cenderung konsisten di seluruh arsip video dan mata pelajaran dan disiplin ilmu. Gaya yang digunakan oleh sebagian besar video instruksional di UT TV adalah gaya slide, baik sebagai gaya utama maupun gaya pendukung. Gaya slide tersebut sangat identik dengan format presentasi yang dapat kita temui dalam perkuliahan konvensional, di mana slide tersebut diposisikan sebagai alat bantu presenter saat menyampaikan materi agar mudah ditangkap dan dipahami oleh audiens.

\section{DAFTAR PUSTAKA}

Bates, A. (. (2005). Technology, E-learning and Distance Education Second Edition. New York: Routledge.

Eriyanto. (2011). Analisis Isi: Pengantar Metodologi untuk Penelitian Ilmu Komunikasi dan Ilmu- ilmu Sosial Lainnya . Kencana.

Espino, J. M., \& Artal, C. G. (2016). Speakers and boards: A survey of instructional video styles in MOOCs. Technical Communication, 101-115.

Grosseck, G., \& Malita, L. (2017). Learning with social media. Researchers in Adult Learning and Education: The European Dimension, 195-203.

Guo, P. J. (2014). How video production affects student engagement: An empirical study of MOOC videos. Proceedings of the first ACM Conference on Learning at Scale (pp. 41-50 ). New York: Association for Computing Machinery .

Guo, P. J., Kim, J., \& Rubin, R. (2014). How Video Production Affects Student Engagement: An Empirical Study of MOOC Videos. The First ACM Conference on Learning@Scale Conference. L@S'14.

Hartsell, T., \& Yuen, S. C.-Y. (2006). Video Streaming in Online Learning. AACE Journal, 14(1), 31-43.

Herring , S. C. (2009). Web Content Analysis: Expanding the Paradigm.

Kizilcec, R. F., Bailenson, J. N., \& Gomez, C. J. (2015). The Instructor's Face in Video Instruction: Evidence From Two Large-Scale Field Studies . Journal of Educational Psychology .

Krippendorff, K. H. (2004). Content Analysis: An Introduction to Its Methodology. SAGE Publications.

Padmo, D., \& Pribadi, B. (2002). Media dalam Pendidikan Terbuka dan Jarak Jauh. In D. Andriani (Ed.), Pendidikan Terbuka dan Jarak Jauh (pp. 36-56). Jakarta: Universitas Terbuka.

Pribadi, B. A., \& Sutjiatmo, B. (2002). Pemanfaatan Siaran TV Pendidikan. In T. Belawati, Pendidikan Terbuka dan Jarak Jauh (pp. 140-148). Universitas Terbuka.

Zhang, D. Z. (2006). Instructional video in e-learning: Assessing the impact of interactive video on learning effectiveness. Information \& management, 43(1), 15-27. 